\title{
Microcephaly in ancient Greece-The Minoan Microcephalus of Zakros
}

\author{
Nikolaos Ch. Syrmos
}

Published online: 12 February 2011

(C) Springer-Verlag 2011

Microcephaly is a neurodevelopmental disorder in which the circumference of the head is more than two standard deviations smaller than average for the person's age and sex. Microcephaly may be congenital or it may develop in the first few years of life. The disorder may stem from a wide variety of conditions that cause abnormal growth of the brain or from syndromes associated with chromosomal abnormalities. The eterogenity of the condition poses problems for clinical evaluation as well as biological, genetic and antropological analyses [1-8].

These are the figures (Figs. 1 and 2) of a microcephalic skull that was found on Zakros, one of the major Minoan (Knossos, Faistos, Zakros and Malia) archaeological sites of Minoan Crete (Figs. 3 and 4) [1-8].

The Minoan civilization, a Bronze Age civilization, arose on the island of Crete and flourished from approximately the twenty-seventh century BC to the fifteenth century BC. It was rediscovered at the beginning of the twentieth century through the work of the British archaeologist Sir Arthur Evans. Will Durant referred to it as "the first link in the European chain" [3-6].

The cranium was excavated from a Minoan Period grave dated about 4,000 years ago and was preserved and studied

N. Ch. Syrmos

Neurosurgery Department, Venizeleio General Hospital,

Heraklion, Crete, Greece

N. Ch. Syrmos $(\bowtie)$

Papafi 159, P.C. 54453,

Thessaloniki, Macedonia, Greece

e-mail: milanako76@yahoo.gr first by Dr. A. Poulianos in 1975 and later by Dr. G. A. Lyras in 2009 [1-6].

The skull is of a person about 20 years old. It was buried in a very small chest-shaped coffin, which suggests a short stature for the individual. The width of the skull is narrow in comparison with the length, the frontal bone retreats, and there is alveolar prognathism and a well-developed mental prominence ago [1-6].

According to experts, this skull belongs to a Homo floresiensis. H. floresiensis has been attributed to a species of its own, a descendant of Homo erectus or another early hominid, a pathological form of Homo sapiens, or a dwarfed H. sapiens [1-8].

This fact reflects probably a genetic diversion connected to long-term isolation and endogamy of Minoans. Thus neither Cretans, nor members of the Minoan dynasty were immigrants from elsewhere, but a result of local evolution [1-6].

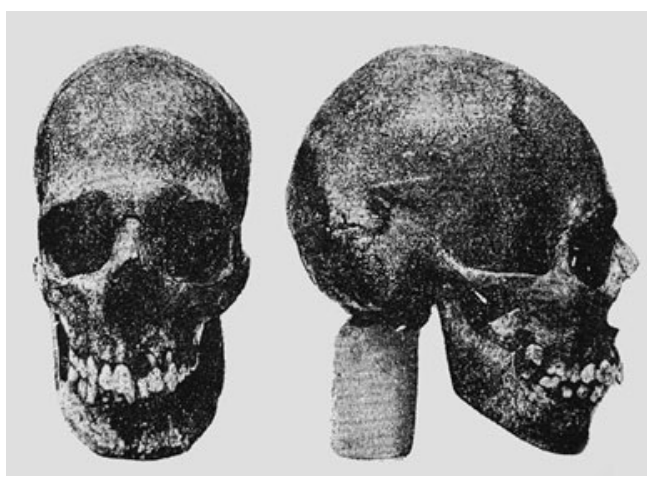

Fig. 1 The cover illustration shows "The Minoan Microcephalus of Zakros". Reproduced with kind permission from N. A. Poulianos (frontal and lateral view) 
Fig. 2 The Minoan Microcephalus of Zakros. Reproduced with kind permission from G. A. Lyras (dorsal and lateral view)

Fig. 3 Zakros, Crete

Fig. 4 Map of Minoan Crete
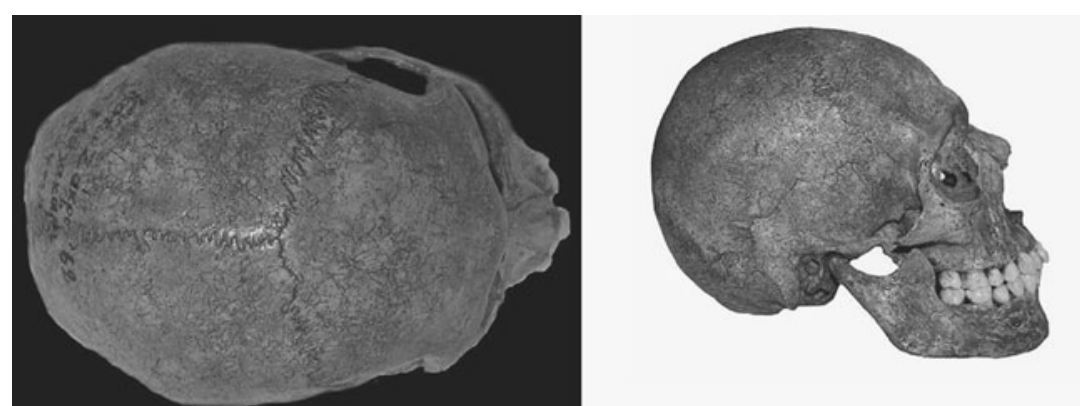
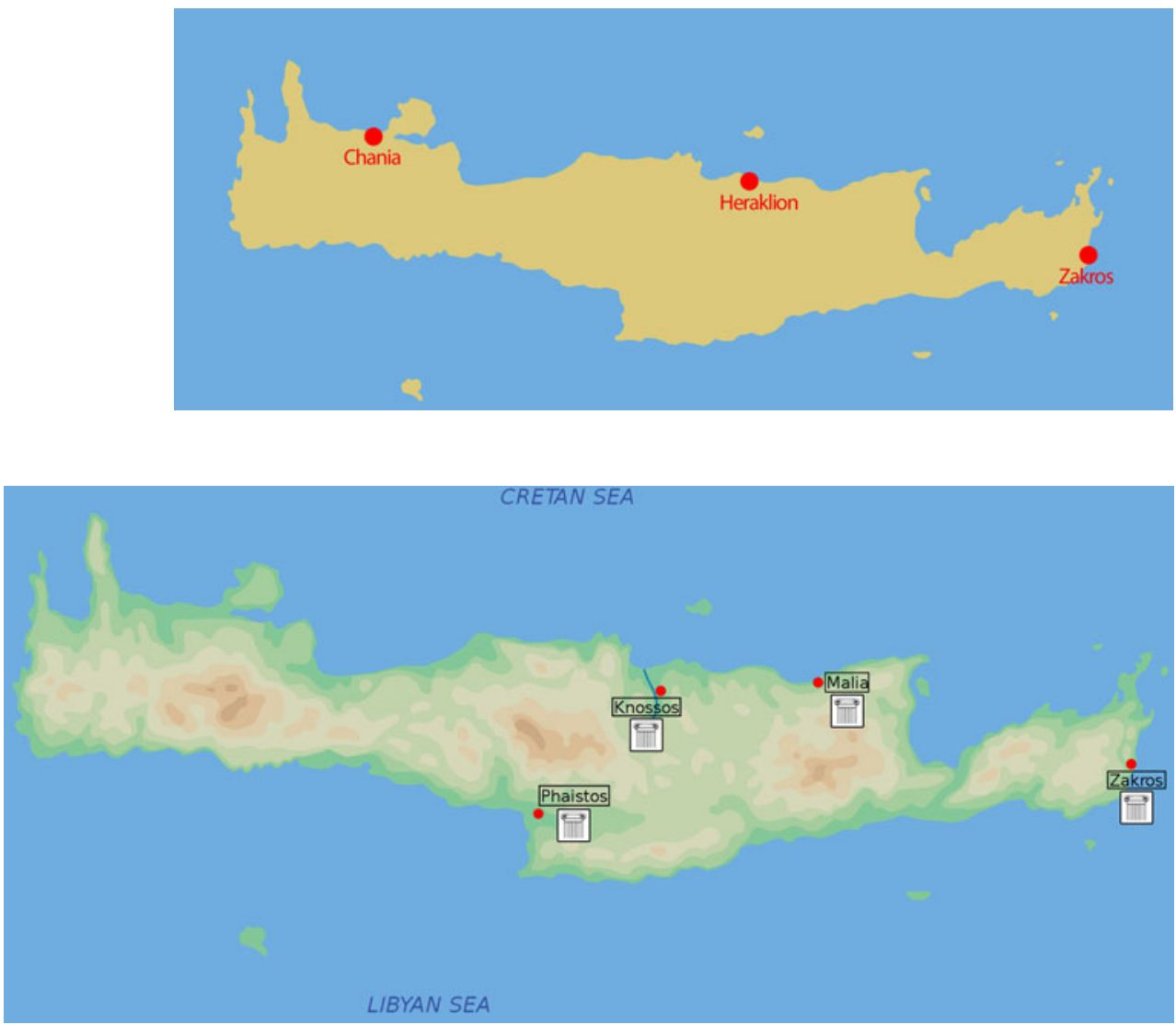

\section{References}

1. Argue D, Morwood MJ, Sutikna T, Jatmiko SEW (2009) Homo floresiensis: a cladistic analysis. J Hum Evol 57(5):623-639

2. Argue D, Donlon D, Groves C, Wright R (2006) Homo floresiensis: microcephalic, pygmoid, Australopithecus, or Homo? J Hum Evol 51(4):360-374

3. Durant W (1939) The life of Greece the story of civilization, part II. Simon \& Schuster, New York

4. Lyras GA, Dermitzakis DM, Van Der Geer AAE, Van der Geer SB, De Vos J (2009) The origin of Homo floresiensis and its relation to evolutionary processes under isolation. Anthropol Sci 117(1):33-43

5. Mochida G, Walsh $\mathrm{CH}$ (2001) Molecular genetics of human microcephaly. Curr Opin Neurol 14(2):151-156

6. Poulianos AN (1975) An early Minoan microcephale. Anthropos 2:40-47

7. Syrmos N. (2007) Historical back training in most important points of neurosurgery. Master thesis, Thessaloniki, Macedonia, Greece (in Greek)

8. Syrmos N, Ampatzidis G, Fachantidou A, Mouratidis I, Syrmos Ch (2010) Historical back training in most important points of neurosurgery. Ann Gen Psychiatry 9(1):S89 